\title{
Spatial interactions of taste stimuli on the human tongue
}

\author{
VIRGINIA B. COLLINGS, LAUREN LINDBERG, and DONALD H. McBURNEY \\ University of Pittsburgh, Pittsburgh, Pennsylvania 15260
}

\begin{abstract}
Two nearby loci on the human tongue were stimulated with solutions representing the four basic taste qualities. The recognition threshold for each test stimulus was measured when a strong concentration of one of the four qualities or water was placed nearby. Decreased sensitivity for the test stimulus resulted when both stimuli were the same quality, with the exception of an enhancement of bitter sensitivity by QHCl. The only effect across qualities was a suppression of citric acid by $\mathrm{NaCl}$. In contrast, classical studies reported across-quality enhancement. Stimulation of two loci on the same half of the tongue and the use of modern psychophysical techniques may explain the differences between these and earlier results.
\end{abstract}

The question of the existence of spatial interactions on the taste receptor surface has been investigated using anatomical, electrophysiological, and psychophysical procedures. There is some anatomical evidence for spatial interactions on the tongue of the rat. It has been known for some time that a single taste receptor may be innervated by more than one nerve fiber and conversely one fiber may innervate several taste receptor organs (Whiteside, 1927). Electron microscopy has shown that nerve fibers branch profusely in the region below the rat's taste bud (Beidler, 1969). Electrophysiological findings also suggest that there may be spatial interactions on the tongue. Rapuzzi and Casella (1965) and Filin and Esakov (1968) observed that action potentials could be propogated antidromically in frog gustatory nerve fibers by electrical and chemical stimulation of adjacent fungiform papillae. Presumably the antidromic impulses coming toward a papilla would block impulses from that papilla to the central nervous system. Miller (1971) showed that rat chorda tympani responses from stimulation of one papilla could be enhanced or depressed by chemical stimulation of surrounding papillae. Sodium chloride to the surround enhanced the response to the same chemical, whereas potassium benzoate to the surround depressed the sodium chloride response.

The terms "contrast" or "simultaneous contrast" have been used in psychophysical taste literature to refer to the enhancement of a taste sensation on one tongue area by simultaneous stimulation of a neighboring area. Both enhancement and suppression have been reported. The earliest study (Kiesow, 1894) reported contrast (enhancement) between sodium chloride and sucrose, between sodium

These results were reported at the meeting of the Psychonomic Society, Boston, November 1974. Supported by USPHS Grant SR01 07873 to D. H. McBurney. Requests for reprints should be addressed to: Donald H. McBurney. Department of Psychology. University of Pittsburgh, Pittsburgh, Pennsylvania 15260. chloride and hydrochloric acid, and between sucrose and hydrochloric acid. Bujas (1937) used stronger solutions than Kiesow had and studied only sodium chloride and sucrose. He found that either contrast or inhibition (suppression) occurred as a function of the concentration of the inducing stimulus. Low concentrations of sucrose lowered the salt threshold, but more concentrated solutions of sucrose raised the salt threshold. Bujas also reported that salt on one area of the tongue would raise the threshold for salt on another area. More recently, McBurney (see Pfaffmann, Bartoshuk, \& McBurney, 1971) replicated Bujas' experiments using a flow system and more modern psychophysical methods and found no significant contrast between salt and sucrose. It was concluded that the earlier results may have been duc to a criterion shift by the subject when a second stimulus was presented.

In all of the psychophysical studies cited, two areas on the opposite sides of the median sulcus of the front of the tongue were stimulated. Since each side of the tongue is served only by the ipsilateral chorda tympani, spatial interactions of a peripheral origin would have to occur within the area innervated by the branches of one nerve; that is, on one side of the median sulcus. Interactions between opposite sides of the tongue would have to have a central origin. In order to maximize the possibility of finding interactions, it seemed best to confine the stimuli to the same half of the tongue. Therefore. in this study, taste recognition thresholds were determined while either water or a constant concentration of an inducing stimulus was presented to an adjacent area on the same side of the tongue.

\section{METHOD}

\section{Subjects}

Two subjects were experienced taste-experiment participants and were informed of the purpose of the study. The other 10 subjects were students at the University of Pittsburgh who were paid for 


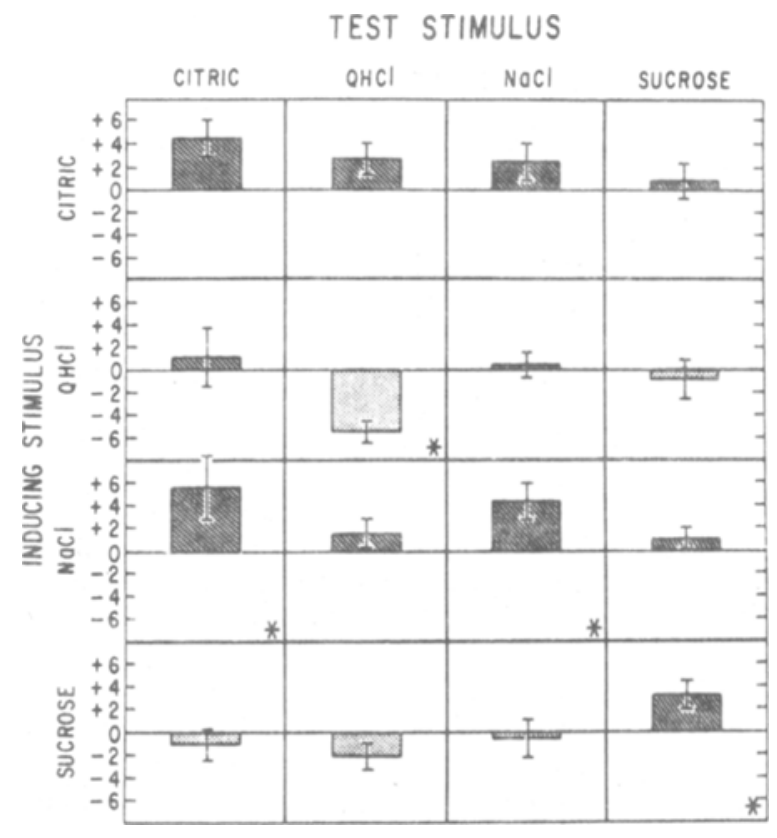

IBRACKETS INDICATE \pm ISE $\overline{\bar{x}}$ * SIGNIFICANT BY I TEST AT OS

Figure 1. Each block indicates the average effect of an induchng stimulus on a test stimulus threshold. The base line bs the tent atimulus threshold when water was present as the inducing stimulus. Changes in the test stimulus threshold are indicated in 10ths of a $\log$ unit.

their participation in the experiment; none smoked and all were naive as to the purpose of the experiment. There was a total of 7 males and 5 females. Each subject participated in five 1-h sessions.

\section{Solutions}

The inducing stimuli were $2.24 \mathrm{M}$ sucrose, $.063 \mathrm{M}$ citric acid, $.0016 \mathrm{M}$ quinine hyd rochloride, and $3.0 \mathrm{M}$ sodium chloride. These were chosen to taste equally intense to the front of the tongue and to be fairly strong. The test stimuli were solutions of the same four chemicals in $0.1 \mathrm{log}$ molar steps, made with deionized water. Sodium chloride and citric acid were reagent grade; quinine, U.S.P.; and sucrose, commercial.

\footnotetext{
Pzychophysical Method

A four-alternative forced-choice procedure was used to determine the recognition threshold of each test stimulus. The compound presented on each trial was randomly determined, with the threshold for each being determined by a tracking procedure (Cornsweet, 1962). The four compounds were tracked simultaneously, with the concentration of the stimulus being increased or decreased by $0.1 \log$ step, depending on that subject's response on the last presentation of that stimulus. After the initial reversal, the mean (geometric) of the molar concentrations where the next six reversals occurred was taken as the measure of the threshold for each stimulus; if six reversals were obtained for one stimulus before completing the tracking for the other three, the tracking was continued for that stimulus, with the mean of the six reversals after the first being used. A preliminary test was used to determine the starting concentrations for the first subject; after that time, each subject was started at the concentration where the previous subject's last reversal on that compound had occurred.
}

\section{Procedure}

The subject first rinsed his mouth with deionized water, and then extended his tongue for the presentation of the stimuli. The stimulator was a round piece of filter paper, $4.0 \mathrm{~mm}$ in diam, which was dipped into a solution, the excess drained off by touching the side of the cup, and placed on the subject's tongue with small forceps. Two stimuli were presented to the tongue: a test stimulus and either an inducing stimulus or water. The stimuli were placed adjacent to marks made by a felt-tipped pen to the right of the median sulcus and $7 \mathrm{~mm}$ apart on center. The test stimulus was always presented to the same spot and approximately 1 sec after the inducing stimulus or water. After placement of the stimuli, the subject kept his tongue extended until he made his response by pointing to a card bearing the name of the taste quality-salty, sour, sweet, or bitter. He then rinsed his mouth twice with deionized water. The experimenter gave the subject feedback after each trial. A record was kept by the experimenter of the nature of all incorrect responses. The intertrial interval was $20 \mathrm{sec}$. An experimental session consisted of the completion of the tracking procedure for one inducing stimulus. The inducing stimuli were presented in a different random order for each subject. This filter paper procedure, devised by Hara (1955) and later used by Collings (1974), allows the discrete localization of the stimulus and makes it possible to check placement during the stimulation process.

\section{RESULTS}

Figure 1 indicates the results. Each row represents one of the inducing stimuli, and each column a test stimulus. In each case, the base line, or reference threshold, for each test stimulus is its threshold when water was presented to the adjacent locus. Each block, then, indicates whether the average effect of a given inducing stimulus on one test stimulus was an increase or a decrease in threshold, shown in 10ths of a $\log$ unit. The standard error of the mean is shown to indicate variability. In addition, the asterisks indicate which effects were significant at $p<.05$ by a $t$ test (two-tailed). When both stimuli were the same, there was a decreased sensitivity to the test stimulus, with the exception of quinine, which showed enhancement. The single other significant effect was the suppression of citric acid by sodium chloride. Table 1 indicates the actual molar threshold values for the test stimuli under all conditions.

A matter of concern in this experiment was that the subject might confuse the test stimulus with the inducing stimulus and thus artificially lower the threshold of the test stimulus when they had the same quality. The incorrect responses given in the presence of water and each of the inducing stimuli were analyzed by means of the Cochran $Q$ test (Siegel,

Table 1

\begin{tabular}{llllll}
\multicolumn{5}{c}{ Mean Thresholds $(\mathbf{M})$ for Test } & Stimuli \\
\hline $\begin{array}{c}\text { Test } \\
\text { Stimulus }\end{array}$ & Water & $\begin{array}{c}\text { Citric } \\
(.063 \mathrm{M})\end{array}$ & $\begin{array}{c}\mathrm{QHCl} \\
(.0016 \mathrm{M})\end{array}$ & $\begin{array}{c}\mathrm{NaCl} \\
(3.0 \mathrm{M})\end{array}$ & $\begin{array}{c}\text { Sucrose } \\
(2.24 \mathrm{M})\end{array}$ \\
\hline Citric & .0032 & .008 & .004 & .012 & .0025 \\
$\mathrm{QHCl}$ & .000026 & .00040 & .000006 & .00004 & .000016 \\
$\mathrm{NaCl}$ & .05 & .079 & .05 & .13 & .040 \\
Sucrose & .028 & .035 & .022 & .035 & .056 \\
\hline
\end{tabular}


1956). The distribution of responses did not differ significantly $(\mathrm{p}>.99$. df $=4)$.

\section{DISCUSSION}

These results do not agree with those of the early studies mentioned. It is possible that the earlier data were the result of a criterion shift occurring when two stimuli were presented at one time: this was the conclusion of McBurney (Pfaffmann. Bartoshuk. \& McBurney. 1971). The present forced-choice procedure should eliminate the possibility of such a criterion shift. Also. as mentioned, the earlier studies looked at interactions across the median sulcus, which would preclude peripheral interactions. It seems unlikely that bilateral interactions would be as strong as those mediated by the same nerve.

In the present study, the suppression of a taste by another stimulus of the same quality would seem to be a consistent effect were it not for quinine's enhancement of quinine. However. it is known that the bitter compounds react differently than the other three basic tastes with respect to cross-adaptation (McBurney. Smith. \& Shick. 1972), so this is perhaps not surprising. The only significant cross-quality effect. the suppression of the citric threshold by sodium chloride. is interesting in that it is not a reciprocal effect; that is, the salt threshold is not significantly affected by citric acid. It does not seem that spatial interactions play a large part in taste perception at distances as large as those used in this study. This conclusion seems consistent with the nature of taste as a system that does not ordinarily deal with questions of spatial patterning of stimuli. On the other hand, evidence from the rat (Miller. 1971) suggests that lateral interactions resulting from the branching of single neurons innervating neighboring papillae may play a part in some of the phenomena involved in coding of quality and the results of mixtures (Bartoshuk. 1975). Such effects. however. involve a very few neighboring papillae within a radius of 2 or $3 \mathrm{~mm}$ in the rat. It is possible that more interactions could be found between taste stimuli if these smaller distances were to be investigated using a center-surround arrangement of the stimuli.

\section{REFERENCES}

BARtoshuK. L. M. Taste mixtures. Physiology and Behavior. $19^{-5}$. in press.

BEIDLER. L. M. Innervation of rat fungiform papillae. In C. Pfaffmann (Ed.). Olfaction and taste III. New York: Rockefeller University Press. 1969.

Bujas. Z. Kontrast- und Hemmungserscheinungen bei disparaten simultanen Geschmacksreizen. Acta Instituri Psychologici Universitatis Zagrebensis. 1937. 2. 3-12.

Collings. V. B. Human taste response as a function of locus of stimulation on the tongue and soft palate. Perception \& Psychophysics. 1974. 16. 169-174.

CORNSwEET. T. N. The staircase method in psychophysics. American Journal of Psychologr. 1962. 75. 485-491.

Filis. V. A., \& EsaKov. A. I. Interaction between taste receptors. Bulletin of Experimental Biology and Medicine (CSSR). 1968. 65. 9-11.

HARA. S. Interrelationship among stimulus intensity. stimulated area and reaction time in the human gustatory sensation. Bulletin of the Tokio Medical and Dental University. $1955,2,14,-158$.

Kiesow, F. Beiträge zur physiologischen Psychologie des Geschmackssinnes. Philosophische Studien. 1894. 10. 523-561.

McBurney. D. H. . S Mith. D. V.. \& SHICK. T. R. Gustatory cross adaptation: Sourness and bitterness. Perception \& Psychophysics. 1972, 11. 228-232.

MilLeR. I. J. Peripheral interactions among single papilla inputs to gustatory nerve fibers. Journal of General Physiology, 1971. 57. 1-25.

Pfaffmann. C.. Bartoshur. L. M.. \& McBurney, D. H. Taste psychophysics. In L. M. Beidler (Ed.). Handbook of sensory physiology (Vol. IV). Chemical senses (Part 2) Taste. Berlin: Springer-Verlag. 1971.

Rapuzzi. G.. \& Casella, C. Innervation of the fungiform papillae in the frog tongue. Journal of Neurophysiology, $1965,28,154-165$.

SIEGEL. S. Nonparametric statistics for the behavioral sciences. New York: McGraw-Hill. 1956.

Whiteside. B. Nerve overlap in the gustatory apparatus of the rat. Journal of Comparative Neurology. 1927. 44. 363-377.

(Received for publication March 26. 1975; revision received October 13.1975 .) 